\title{
Engaging College Students On A Community Engagement With High School Students With Disabilities
}

James Lawler, Pace University, USA

Anthony Joseph, Pace University, USA

Stuti Narula, Pace University, USA

\begin{abstract}
Community engagement is a common course in college curricula of computer science and information systems. In this study, the authors analyze the benefits of digital storytelling, in a course engaging college students with high school students with disabilities. The authors discover that a project of storytelling progressively enables high engagement of the students, in importance, performance, and satisfaction. The authors also discover that the project enables progressively high impact in the advocacy of these students for individuals with disabilities, in self-efficacy and sociality. The study will benefit instructors in any discipline evaluating digital storytelling technology as a service-learning tool.
\end{abstract}

Keywords: Community Engagement; Digital Storytelling; High School Students with Disabilities; Information Systems Curriculum; Service-Learning

\section{BACKGROUND OF PAPER}

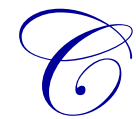

ommunity engagement is a “... approach in learning ... that integrates community service with academic [courses] to enrich learning [and] teach civic responsibility ..., engaging [college] students in addressing [an] unmet issue ... in a community" (Pritchard \& Whitehead, 2004) evident in colleges (Iimoto, 2013). The design of the learning in this paper is in a project of service attempting to benefit college students engaged with high school students with developmental and intellectual disabilities (e.g., autism) and to benefit the high school students themselves. The history of individuals with disabilities is considered to be of disempowerment and invisibility (Willis, 2012) if not exclusion from society (Bingham, Spooner, \& Browder, 2007) that is not frequently known by college students not having disabilities. The lives of individuals with disabilities, not merely as individuals with disabilities but of persons with potential, are not considered to be explored frequently nor heard in life passports and storybooks (Middleton \& Hewitt, 1999) or reflective stories by themselves. Such stories can be a foundation for grit and self-determination if not self-identity (Skouge, Kelly, Roberts, Leake, \& Stodden, 2007) that if helped by the college students may inspire the lives of individuals with disabilities (Skouge, Kelly, Roberts, Leake, \& Stodden, 2007). These stories can be furnished in a media of digital storytelling (DST) (Ohler, 2013) or visual storytelling (Dow, 2012) that can give a persistence and voice to individuals with disabilities (Skouge, 2007).

Visual storytelling is defined in the literature as a “... combination of emotional [attitude] and narrative information ..., [furnishing] a barely perceptible emotional context to the telling of the ... narrative [that] is the same as any successful story" (Klanten, Ehmann, \& Schulze, 2011). The lives of high school students with developmental and intellectual disabilities who are still verbal can be expressed by these students through narratives of visual storytelling (Grove, 2007). The media of the narratives or visual storytelling can be a mix of fundamental graphic, photographic and textual technology and movie-making, musical (Tietze, 2012) and soundtrack tools or other technological tools (Bers, 2010). The narratives of reconstructions or situations of the high school students can be the products of a project in a community engagement course of college students without disabilities helping 
the high school students with disabilities in the recording and sharing of the visual storytelling through the tools. The engagement process of visual storytelling can be helpful to the college students in learning about individuals with disabilities and to the high school students with disabilities in learning about methods of representing their situations and themselves (Booth \& Booth, 2003).

The benefits of a community engagement course of college students on a project of stories of high school students with disabilities are in the actual engagement with the high school students and in the formation of advocacy for the high school students. Helped by the college students, the high school students with developmental and intellectual disabilities are enabled to express self-determination in life optimization and planning (Schnapp \& Olsen, 2003; Skouge, Kelly, Roberts, Leake, \& Stodden, 2007). Media projects of visual storytelling can facilitate grit, if not motivate a persistent self-determination of these high school students in societal transition and visioning (Skouge, Kelly, Roberts, Leake, \& Stodden, 2007), if helped by the college students. The engagement of the college students on the storytelling can be helpful in learning about a marginalized population that can have meaningful potential in society (Danforth, 2001), formulating advocacy for this population. Not clear however is the extent of engagement and advocacy impacts of a project of visual storytelling on the college students without disabilities and of course on the high school students with disabilities. The authors analyze the impacts on the college students in this first study.

\section{INTRODUCTION TO PROJECT}

The authors of this study analyze engagement and advocacy impacts of visual storytelling in a community engagement course, at the Seidenberg School of Computer Science and Information Systems at Pace University. The course concentrates on a project of autobiographical visual storytelling at the AHRC New York City Middle/High School, an institution for high school students with developmental and intellectual disabilities. The essence of the course is for the high school students to be helped by the college students in the development of narratives or stories through visual storytelling tools. The goals of the course are helping in the improvement of self-identity of the high school students, and helping in the improvement of self-knowledge of the college students of a neglected population of high school students. The outcomes of the project are in the impacts of increased responsibility in service by the college students without disabilities and increased support to the high school students with disabilities.

The course consists of 35 college students for the Fall 2012 semester and 28 students for the Spring 2013 semester, or 63 students for the current study. Each of the college students, from freshmen to senior students, is paired by the author-instructor with a higher-functioning (i.e., less impaired) high school student with disabilities at the beginning of each semester for the duration of the semester. Few of the college students are experienced with individuals with developmental and intellectual disabilities or were even exposed to neighborhood service (Lawler, 2012). They are guided by the instructor, the first author of this study, in a conceptualized discovery process for developing person-centered stories (Mount \& Zwernik, 1988), though the process is of limited scaffolding (Repenning, 2012), or limited step-by-step instructions (Bamberg, 1997), so that it does not stifle the imagination of the students (Willis, 2012). The focus of the project is the recording and sharing of hopes, joys, and interests (Holburn, Gordon, \& Vietze, 2007) in personalized stories of the high school students each week, through largely marketplace mobile multimedia technology fully known to the college students (Tapscott, 1997), if not the high school students.

Helped by the college students, the high school students may express and form storyboards through audio recording of scripts, photographic slide showing, and recording of sounds and videos of digital camera and smartphone technology. Adobe Creative Suite, GoAnimation!, image-edifying software, mikes, iMovie, Movie Maker II, and Windows Media Player are frequent tools, already housed at the high school and the university and generally known to digital native students (Peterson, 2013). The high school students and the college students are currently partnered on the technology and the tools on-site at the university 3 hours 1 day each week for 14 semester weeks, with planned presentations of the visual storytelling on the $14^{\text {th }}$ week to the families and the high school staff so that the project has a meaning and a publicized purpose (Hathaway \& Norton, 2012). 
Literature indicates that media presentations of visual storytelling can motivate the high school students with disabilities in options of post secondary school transition (Skouge, Kelly, Roberts, Leake, \& Stodden, 2007). Inter-personal skills can be learned by the high school students, as they may be motivated by the partnerships with the college students in the productions of societal transition visualization. The projects can motivate the college students (Hoxmeier \& Lenk, 2003) in service to the high school students. Following each week, the college students are currently required to furnish anecdotal engagement journals (Moon, 2004) to the instructor reflecting the ongoing progress and their relationships on the visual storytelling. From these journals, especially from mid-term and final semesters, the author can analyze the engagement and advocacy impacts of the project on the college students without disabilities in this particular study.

Therefore, this study evaluates the extent of engagement and advocacy impacts of this project of visual storytelling on the college students. Video production with individuals with disabilities can contribute in high engagement of college students from the importance, performance, and satisfaction of visual storytelling (Hathaway \& Norton, 2012); and in high impact in the advocacy of the college students from the self-efficacy and sociality of the students for the individuals. Is this project of visual storytelling, as practiced at Pace University, definitely enabling high engagement of the college students from the importance, performance, and satisfaction of the project; and is this project of visual storytelling, as practiced at the university, definitely enabling high impact of advocacy from the self-efficacy and sociality learned on the project? Few studies evaluate the impacts of new media projects on college students without disabilities as they are partnered with this population of society on visual storytelling.

\section{FOCUS}

The paper analyzes engagement and advocacy from a project in a community engagement course at their school of the university. They center on the impacts of visual storytelling on the college students without disabilities. The factors of the study are formed below:

\section{Engagement of College Students}

- Importance - Extent of impact from which the college students without disabilities perceive processes of visual storytelling in facilitating meaningful partnerships with the high school students with disabilities;

- $\quad$ Performance - Extent of impact from which the college students perceive the technologies of visual storytelling in facilitating productions of the semesters with the high school students; and

- $\quad$ Satisfaction - Extent of impact from which the college students perceive the productions of visual storytelling in furnishing satisfaction with the results of the semesters with the high school students.

\section{Advocacy of College Students}

- $\quad$ Self-Efficacy - Extent of impact from which the college students without disabilities perceive the potential of visual storytelling in furnishing a foundation for them to be advocates that can effect a difference for individuals in society; and

- $\quad$ Sociality - Extent of impact from which the college students perceive the potential of visual storytelling in influencing a motivation for them to be involved in other programs of service with individuals with disabilities in the university.

The formulation is derived from a previous study of the authors (Lawler \& $\mathrm{Li}$, 2005) and from recent service-learning sources (Lee, 2012) and studies of the technologies (Mirza, Anandan, Madnick, \& Hammel, 2006). The study is not focusing on the impacts on the high school students with disabilities, which will be analyzed in a future separate study. This study of college students without disabilities can benefit community engagement instructors evaluating the growing influence (MacLaury, Frank, Vidar, Gillum, \& Klayman, 2012) of self-advocacy visual storytelling in the service-learning of students in a university.

\section{RESEARCH METHODOLOGY}

The research methodology of this study consisted of a population of 63 college students without disabilities in the community engagement course of the instructor at the Seidenberg School of Computer Science and 
Information Systems of Pace University. The methodology covered 35 students in the Fall 2012 semester and 28 students in the Spring 2013 semester. The projects of visual storytelling were evaluated by the primary author in the following manner:

- A checklist pre-course instrument survey was performed of each of the college students as to their experience of service with individuals with disabilities and their knowledge of visual storytelling; a checklist mid-course and mid-project review of the reflection journals of the students was performed of each of the students as to their perceived learning of service and of visual storytelling at the mid-term $7^{\text {th }}$ week of the semesters; and a checklist post-course and post-project review was performed of each of their reflection journals as to their perceived learning of service and of visual storytelling at the final 14th week of the semesters;

- $\quad$ Reflection journals on the service and on the visual storytelling were posted by the college students as a course requirement on to an e-Portfolio system of the university, from which the first author reviewed the journals;

- $\quad$ The learning and the service in the reflection journals of the college students was reviewed from the extent of engagement impacts, measured by perceived importance, performance and satisfaction of the students, and from the extent of advocacy impacts, measured by perceived self-efficacy and sociality of the students, following the content methodology of reviewing student writings (Rama, Ravenscroft, Wolcott, \& Zlotkowski, 2000), on a six-point Likert-like rating scale of 5 - very high in impacts to 1 - very low in impacts, with 0 - no impact;

- The progress of the students was also reviewed by observation of the first author throughout the semesters; and

- $\quad$ To lessen halo impacting of the journals, the perceptions of service and of visual storytelling were reviewed further in open questions in a semi-structured focus group of a random sample of 12 Fall 2012 and Spring 2013 students.

The second author of the study evaluated the instruments of the survey and the reviews in the context of construct, content and face validity, including content validity measured in the context of sampling validity.

The second author evaluated moreover the impact results of the first author from the mid-project and final project reviews and from the focus group review; and the second author interpreted the data from the surveys and reviews in the MAT LAB 7.10.0 Statistics Toolbox (McClave \& Sincich, 2006), for the analysis of findings in the following section.

\section{ANALYSIS OF DATA}

The analysis of the data disclosed that the engagement and the advocacy of all of the college students improved progressively from low to high in means 1.51 and 1.75 in the pre-course survey to 3.54 and 3.37 in the mid-course/mid-project review and 4.51 (or 4.00, 5.00, and 5.00 in importance, performance, and satisfaction) and 4.13 (or 4.00 and 4.00 in self-efficacy and sociality) in the post-project review, as expanded in Table 3 below, and illustrated in Figures 1 and 2 below. The engagement and the advocacy of female students improved progressively to high from 1.82 and 2.01 in the pre-course survey to 3.64 and 3.54 in the mid-project review and 4.52 and 4.04 in the post-project review, in Table 1 below; and of male students progressively to high from 0.99 and 1.28 in the precourse survey to 3.36 and 3.09 in the mid-project review and 4.49 and 4.30 in the post-project review, in Table 2 below. The post-course focus group also indicated high engagement in 4.56 for the limited number of all students, female students and male students and high advocacy in 4.38 for the limited number of all students, 4.39 for female students and 4.33 for male students, in Table 4 below. At the same time, those students not experienced in service or volunteering improved progressively in engagement and advocacy from low means of 0.00 and 1.00 in the precourse survey to high means of 4.00 and 4.00 in the post-project reviews. Those students not experienced or immediately knowledgeable with individuals with disabilities improved similarly in the engagement and the advocacy from low means of 1.00 and 1.00 in the pre-course survey to high means of 4.00 (or 4.00, 4.00, and 5.00 in importance, performance, and satisfaction) and 4.00 (or 4.00 and 4.00 in self-efficacy and sociality) in the postproject reviews. 
The findings are encouraging in the impact of the projects, as few of the students had experienced service or volunteering $(n=11 / 63)$, interactions with individuals with developmental and intellectual disabilities $(n=5 / 63)$, or visual storytelling $(n=3 / 63)$ prior to the course. The reflection journals at the mid-term $7^{\text {th }}$ and final $14^{\text {th }}$ weeks of the semesters implied in self-efficacy and sociality the learning of service; and in importance, performance, and satisfaction the power of visual storytelling in servicing the high school students with disabilities. These journals frequently indicated that the students were individually motivated, and motivated by the high school students, to be more involved with the high school students through the visual storytelling, which even motivated the students of the course to be involved with the families of a few of the high school students with disabilities. The findings of the engagement and the advocacy improving progressively in the course indicated the impact of visual storytelling in learning about servicing a marginal population of society.

Other analysis of the correlation of the data indicated that the findings were significant statistically for each pair of the components of importance, performance, and satisfaction of engagement and of self-efficacy and sociality of advocacy, as in Tables 5 and 6 below. The values were at the interactions of these components. The Wilcoxon rank sum testing, helpful in interpreting the data from the different number of female $(\mathrm{n}=40)$ and male $(\mathrm{n}$ $=23$ ) students in a sample skewed, and more robust than the t-test, indicated that there were no significant statistical variances in the results of the female and male students for each of the components of the engagement and of the advocacy, as in Table 7 below.

Table 1: Engagement and Advocacy of College Students - Female Students $(n=40)$

Fall 2012 and Spring 2013 Semesters - Means and Standard Deviations

\begin{tabular}{|l|c|c|c|}
\hline \multicolumn{1}{|c|}{ Factors of Study } & Pre-Course Survey & $\begin{array}{c}\text { Mid-Course/Mid-Project } \\
\text { Review }\end{array}$ & $\begin{array}{c}\text { Post-Course/Post-Project } \\
\text { Review }\end{array}$ \\
\hline Engagement Means & 2.00 & 4.00 & 4.00 \\
Importance & 2.00 & 4.00 & 4.00 \\
Performance & 2.00 & 3.00 & 5.00 \\
Satisfaction & 1.82 & 3.64 & 4.52 \\
\hline Means & 1.88 & 1.11 & 0.67 \\
\hline Standard Deviations & & & 4.00 \\
\hline Advocacy Means & 2.00 & 4.00 & 4.00 \\
Self-Efficacy & 2.00 & 3.00 & 4.04 \\
Sociality & 2.01 & 3.54 & 0.88 \\
\hline Means & 1.84 & 1.10 & \\
\hline Standard Deviations & & & \\
\hline
\end{tabular}

Rating Scale: 5 - Very High in Impacts, 4 - High, 3 - Intermediate, 2 - Low, 1 - Very Low, and 0 - No Impacts

Table 2: Engagement and Advocacy of College Students - Male Students $(n=23)$

Fall 2012 and Spring 2013 Semesters - Means and Standard Deviations

\begin{tabular}{|l|c|c|c|}
\hline \multicolumn{1}{|c|}{ Factors of Study } & Pre-Course Survey & $\begin{array}{c}\text { Mid-Course/Mid-Project } \\
\text { Review }\end{array}$ & $\begin{array}{c}\text { Post-Course/Post-Project } \\
\text { Review }\end{array}$ \\
\hline Engagement Means & 1.00 & 4.00 & 4.00 \\
Importance & 1.00 & 3.00 & 5.00 \\
Performance & 1.00 & 3.00 & 5.00 \\
Satisfaction & 0.99 & 3.36 & 4.49 \\
\hline Means & 1.79 & 1.39 & 0.72 \\
\hline Standard Deviations & & & 4.00 \\
\hline Advocacy Means & 1.00 & 3.00 & 4.00 \\
Self-Efficacy & 1.00 & 3.00 & 4.30 \\
Sociality & 1.28 & 3.09 & 0.84 \\
\hline Means & 1.96 & 1.56 & \\
\hline Standard Deviations & & & \\
\hline
\end{tabular}


Table 3: Engagement and Advocacy of College Students -All Students $(n=63)$ Fall 2012 and Spring 2013 Semesters - Means and Standard Deviations

\begin{tabular}{|l|c|c|c|}
\hline \multicolumn{1}{|c|}{ Factors of Study } & Pre-Course Survey & $\begin{array}{c}\text { Mid-Course/Mid-Project } \\
\text { Review }\end{array}$ & $\begin{array}{c}\text { Post-Course/Post-Project } \\
\text { Review }\end{array}$ \\
\hline Engagement Means & & & 4.00 \\
Importance & 2.00 & 4.00 & 5.00 \\
Performance & 1.00 & 4.00 & 5.00 \\
Satisfaction & 2.00 & 3.00 & 4.51 \\
\hline Means & 1.51 & 3.54 & 0.69 \\
\hline Standard Deviations & 1.89 & 1.22 & 4.00 \\
\hline Advocacy Means & & 3.00 & 4.00 \\
Self-Efficacy & 2.00 & 3.00 & 4.13 \\
Sociality & 2.00 & 3.37 & 0.87 \\
\hline Means & 1.75 & 1.30 & \\
\hline Standard Deviations & 1.91 & & \\
\hline
\end{tabular}

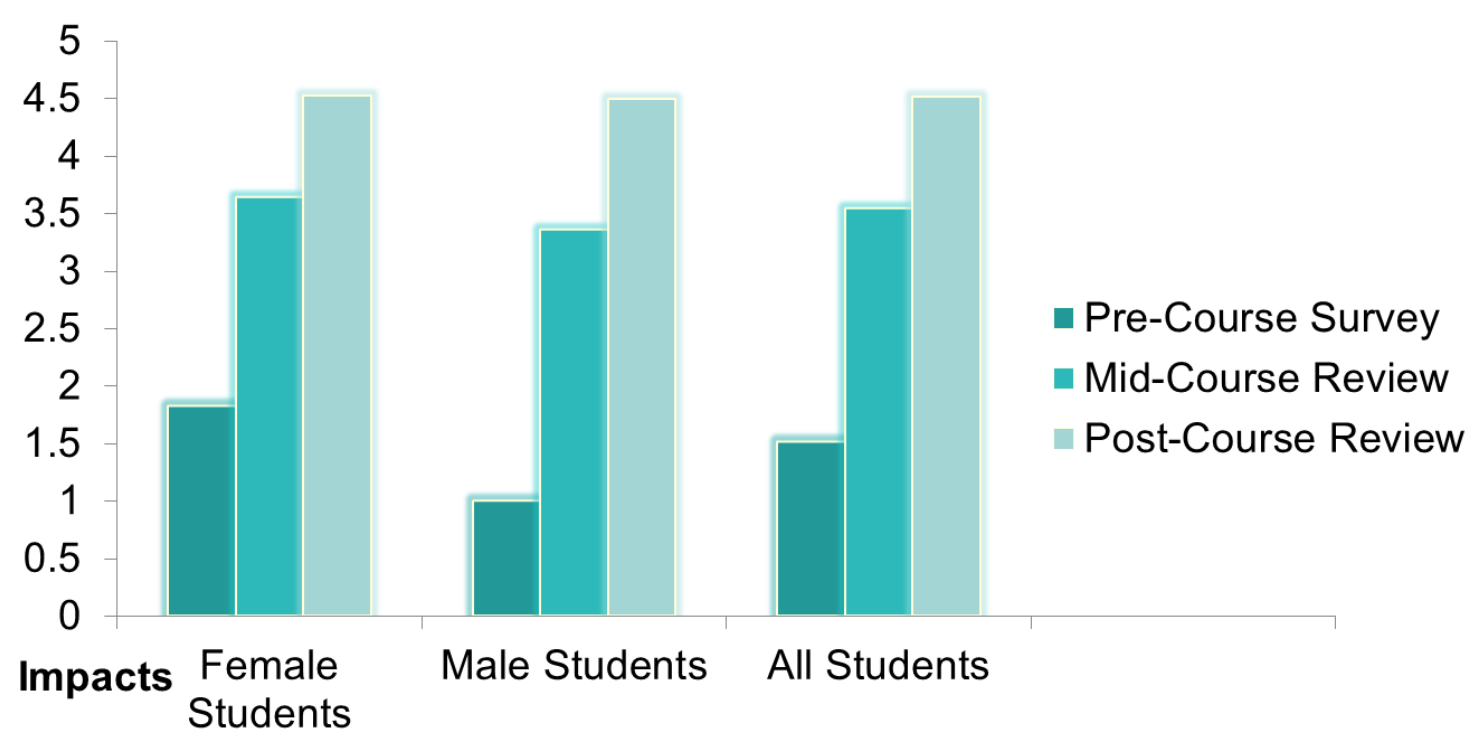

Figure 1: Engagement of College Students - All Students $(n=63)$ Fall 2012 and Spring 2013 Semesters - Means

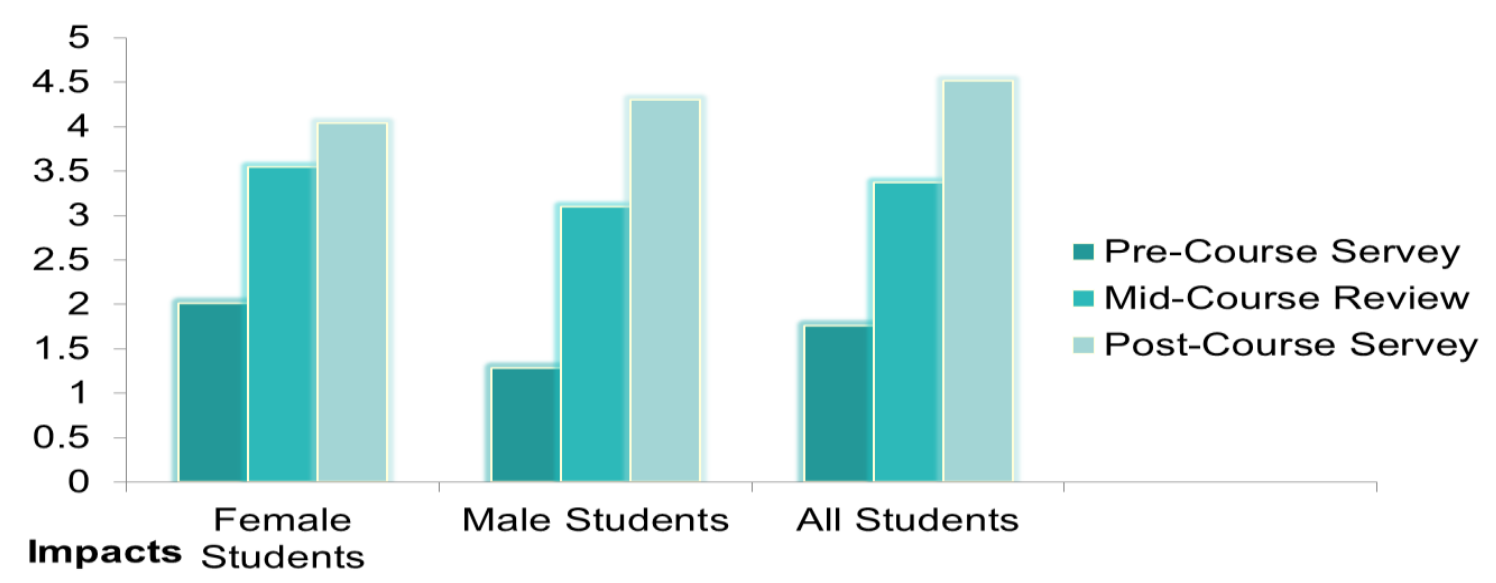

Figure 2: Advocacy of College Students - All Students (n = 63) Fall 2012 and Spring 2013 Semesters - Means 
Table 4: Engagement and Advocacy of College Students -Post- Course Focus Group Students $(\mathbf{n}=12)$ Fall 2012 and Spring 2013 Semesters - Means and Standard Deviations

\begin{tabular}{|l|c|c|c|}
\hline \multicolumn{1}{|c|}{ Factors of Study } & Female Students & Male Students & All Students \\
\hline Engagement Means & & & 5.00 \\
Importance & 4.00 & 5.00 & 5.00 \\
Performance & 5.00 & 5.00 & 5.00 \\
Satisfaction & 5.00 & 4.00 & 4.56 \\
\hline Means & 4.56 & 4.56 & 0.61 \\
\hline Standard Deviation & 0.64 & 0.53 & 5.00 \\
\hline Advocacy Means & & & 4.00 \\
Self-Efficacy & 4.00 & 5.00 & \\
Sociality & 5.00 & 4.00 & 4.38 \\
\hline Means & 4.39 & 4.33 & 0.71 \\
\hline Standard Deviations & 0.70 & 0.82 & \\
\hline
\end{tabular}

Table 5: Engagement and Advocacy of College Students - All Students Fall 2012 and

Spring 2013 Semesters - Correlation of Means - Engagement and Advocacy Ratings

\begin{tabular}{|l|c|c|c|c|c|}
\hline & Importance & Performance & Satisfaction & Self-Efficacy & Sociality \\
\hline Importance & 1.00 & & & & \\
\hline Performance & 0.70 & 1.00 & & & \\
\hline Satisfaction & 0.68 & 0.86 & 1.00 & & \\
\hline Self-Efficacy & 0.67 & 0.71 & 0.81 & 1.00 & \\
\hline Sociality & 0.71 & 0.63 & 0.65 & 0.78 & 1.00 \\
\hline
\end{tabular}

( $\mathrm{p}$-value $=0.00$ for each of the pair of non-diagonal variables of engagement and advocacy in study)

Table 6: Engagement and Advocacy of College Students - All Students Fall 2012 and Spring 2013 Semester - Correlation of Means - Overall Ratings

\begin{tabular}{|l|c|c|}
\hline & Engagement Means & Advocacy Means \\
\hline Engagement Means & 1 & 1 \\
\hline Advocacy Means & 0.79 & 1 \\
\hline
\end{tabular}

(p-value $=0.00$ for correlation of engagement and advocacy in study)

Table 7: Engagement and Advocacy of College Students - All Students Fall 2012 and

Spring 2013 Semesters - Wilcoxon Rank Sum Test of Female and Male Students

\begin{tabular}{|l|c|}
\hline \multicolumn{1}{|c|}{ Components } & Values \\
\hline Engagement & 0.19 \\
Importance & 0.43 \\
Performance & 0.09 \\
Satisfaction & 0.19 \\
\hline Engagement Means & \\
\hline Advocacy & 0.20 \\
Self-Efficacy & 0.25 \\
Sociality & 0.18 \\
\hline Advocacy Means & \\
\hline
\end{tabular}

\section{IMPLICATIONS OF STUDY}

Engagement evaluated progressively high in importance of partnerships, performance of productions, and satisfaction on the project results of the semesters is implying enablement by visual storytelling. Storytelling is considered in the literature to be founded on friendships on person-centered planning projects (Tillmann-Healy, 2003) improved from the technology (Barrett, 2006), and liberating in the reflections of college students (Sandars, Murray, \& Pellow, 2008). The study suggests that on projects with marginalized populations, visual storytelling is an enabler of high engagement of the college students.

Advocacy equally evaluated progressively high in self-efficacy and sociality suggests evident impact of the project service on the college students. Mentoring in general is helpful in influencing individuals (Rhodes, 2002). Storytelling is indicated in the literature to be especially helpful in initiating vocalization of individuals with developmental and intellectual disabilities, even individuals that are non-verbal, such that the high school students 
may be more interested in the actual storytelling (Grove, 2005), motivating the college students to be more interested in the storytelling. The service of storytelling is influencing involvement in other programs of service with the primary author and may influence involvement moreover in programs relating to the disability rights movement (Institute on Disability and Human Development, 2012). The study suggests that projects of storytelling vocalization are enablers of formative social skills of the high school students and a facilitator of formative servicelearning skills in the sociality of the college students - the focused population of this study.

Finally, this study suggests the benefits of having media technology facilitate projects of service-learning involving visual storytelling, furnishing further instructional methodology (Patrick \& Green, 2012). Literature is indicating the opportunities of production technology in instructional strategy (Lankshear \& Knobel, 2003 and Miller, 2007) and of overall rich technologies pleasing to college students (Prensky, 2001). This study suggests that new media production technology, integrated into service-learning and visual storytelling, is an enabler of positive resultant service of the students at Pace University.

\section{CONCLUSION OF PAPER}

The paper analyzes the benefits of engagement of college students with high school students with developmental and intellectual disabilities on projects of digital storytelling. The authors learn that projects of visual storytelling enable progressively high engagement in importance, performance, and satisfaction and progressively high advocacy and altruism in self-efficacy and sociality of the college students. The authors learn that visual storytelling enables generally high inter-personal service-learning skills of the college students and is a powerful service-learning tool. The results suggest that visual storytelling motivates these students to progress into other programs of service. Overall, this study is relevant to instructors in service-learning and to those in other topics interested in integrating visual storytelling as an instructional strategy.

\section{AUTHOR INFORMATION}

James Lawler, D.P.S., is Professor of Disability Studies, Information Technology and Service-Learning in the Seidenberg School of Computer Science and Information Systems of Pace University in New York City and is a recipient of the national Jefferson Award for Community Service in Teaching. E-mail: jlawler@pace.edu (Corresponding author)

Anthony Joseph, Ph.D., is Professor of Computer Science and a researcher and a statistician in the Seidenberg School of the university. E-mail: ajoseph2@ pace.edu

Ms. Stuti Narula is a graduate student in information technology in the Seidenberg School of the university. E-mail: sn429066n@pace.edu

\section{REFERENCES}

1. Bamberg, M. (1997). Narrative development: Six approaches. Mahwah, New Jersey: LEA.

2. Barrett, L. F. (2006). Solving the emotion paradox: Categorization and the experience of emotion. Personality and Social Psychology Review, 10(1), 20.

3. Bers, M. U. (2010). New media and technology: Youth as content creators. New Directions for Youth Development, Winter, 26.

4. Bingham, M. A., Spooner, F., \& Browder, D. (2007). Training paraeducators to promote the use of augmentative and alternative communication by students with significant disabilities. Education and Training in Developmental Disabilities, 42(3), 339.

5. Booth, T., \& Booth, W. (2003). In the frame: Photo-voice and mothers with learning difficulties. Disability \& Society, 18(4), 431-442.

6. Danforth, S. (2001). A Deweyan perspective on democracy and inquiry in the field of special education. Journal of the Association for Persons with Severe Handicaps, 26(4), 270-280.

7. $\quad$ Dow, L. (2012). Visual storytelling. Social Media Today, 2012, March 20, 1-4.

8. Grove, N. (2005). Ways into literature. London, United Kingdom: David Fulton. 
9. Grove, N. (2007). Exploring the absence of high points in story reminiscence with careers of people with profound disabilities. Journal of Policy and Practice in Intellectual Disabilities, 4(4), 252.

10. Hathaway, D., \& Norton, P. (2012). Video production: Bridging teacher education and classroom practice. Journal of Technology and Teacher Education, 20(2), 131, 141, 146.

11. Holburn, S., Gordon, A., \& Vietze, P. M. (2007). Person-centered planning made easy: The picture method. Baltimore, Maryland: Brookes Publishing Company.

12. Hoxmeier, J., \& Lenk, M. L. (2003). Service-learning in information systems courses: Community projects that make a difference. Journal of Information Systems Education, 14(1), 91-100.

13. Iimoto, D. S. (2013). Service-learning in an AIDS course. Science Education and Civic Engagement, 5(1), 25 .

14. Klanten, R., Ehmann, S., \& Schulze, F. (2011). Visual storytelling: Inspiring a new visual language. Berlin, Germany: Gestalten, 4.

15. Lankshear, C., \& Knobel, M. (2003). New literacies: Changing knowledge and classroom learning. Berkshire, United Kingdom: Open University Press.

16. Lawler, J. (2012). Engaging community service students through digital portfolios. Proceedings of the Information Systems Educators Conference (ISECON), New Orleans, Louisiana, November.

17. Lawler, J., \& Li, Z. (2005). Student engagement in a flexible model of service learning in information systems curricula. Journal of Informatics Education Research, 7(2), 53-90.

18. Lee, R. L. (2012). Experience is a good teacher: Integrating service and learning in information systems education. Journal of Information Systems Education, 23(2), 165.

19. MacLaury, S., Frank, L., Vidar, J., Gillum, K., \& Klayman, A. (2012). The growing influence of visual storytelling in advocacy. New York University: Heyman Center for Philanthropy and Fundraising - Panel on Film and Video in Advocacy, March 28, 2.

20. McClave, J., \& Sincich, T. (2006). A first course in statistics, ninth edition. Upper Saddle River, New Jersey: Pearson Prentice Hall.

21. Middleton, D., \& Hewitt, H. (1999). Remembering as social practice: Identity and life story work in transitions of care for people with profound learning disabilities. Narrative Inquiry, 9, 97-121.

22. Miller, S. M. (2007). English teacher learning for new times: Digital video composing as multimodal literacy practice. English Education, 40(1), 6-83.

23. Mirza, M., Anandan, N., Madnick, F., \& Hammel, J. (2006). A participatory program evaluation of a systems change program to improve access to information technology by people with disabilities.

Disability and Rehabilitation, 28(19), 1185-1199.

24. Moon, J. A. (2004). A handbook of reflective and experiential learning. London, United Kingdom: Routledge Falmer.

25. Mount, B., \& Zwernik, K. (1988). It is never too early, it is never too late: A booklet about personal futures planning. Governor's Council on Developmental Disabilities, Minnesota.

26. Ohler, J. B. (2013). Digital storytelling in the classroom: New media pathways to literacy, learning and creativity, second edition (p. 16). Thousand Oaks, California: Corwin.

27. Patrick, D., \& Green, J. (2012). Using emerging technologies to facilitate science learning and civic engagement. Science Education and Civic Engagement, 4(2), 19.

28. Peterson, L. (2013). Understanding generation z. National Youth Leadership Council, $30(2), 1,4$.

29. Prensky, M. (2001). Digital natives, digital immigrants. Part 2: Do they really think differently? On the Horizon, 9(6), 1-6.

30. Pritchard, F. F., \& Whitehead, G. I. (2004). Serve and learn: Implementing and evaluating service-learning in middle and high schools. Mahwah, New Jersey: Lawrence Erlbaum Associates.

31. Rama, D. V., Ravenscroft, S. P., Wolcott, S. K., \& Zlotkowski, E. (2000). Service-learning outcomes: Guidelines for educators and researchers. Issues in Accounting Education, 15(4), 657-692.

32. Repenning, A. (2012). Programming goes back to school. Communications of the ACM, 55(5), 40.

33. Rhodes, J. E. (2002). Stand by me: The risks and rewards of mentoring today's youth. Cambridge, Massachusetts: Harvard University Press.

34. Sandars, J., Murray, C., \& Pellow, A. (2008). Twelve tips for using digital storytelling to promote reflective learning by medical students. Med Teach, 30(8), 774-777.

35. Schnapp, L., \& Olsen, C. (2003). Teaching self-advocacy strategies through drama. Intervention in School and Clinic, 38(4), 211. 
36. Skouge, J. (2007). Assistive technology supports for self-determination and community inclusion. Review of Disability Studies: An International Journal, 3(1-2), 53-62.

37. Skouge, J. R., Kelly, M. L., Roberts, K. D., Leake, D. W., \& Stodden, R. A. (2007). Technologies for selfdetermination for youth with developmental disabilities. Education and Training in Developmental Disabilities, 42(4), 475-477, 480.

38. Tapscott, D. (1997). Growing up digital: The rise of the net generation. New York, New York: McGrawHill.

39. Tietze, R. L. (2012). Music as a resource for adult education experience. Proceedings of the 2012 National Symposium: New Faces, New Expectations, New Orleans, Louisiana, November 17, 7.

40. Tillmann-Healy, L. (2003). Friendship as a method. Qualitative Inquiry, 9(5), 729-749.

41. Willis, J. (2012). Held: To carry a story below. The Children of Freire CCD Journal: New Writings on Community Cultural Development, 1, 3, 5, 7 . 